\title{
ABORDAGEM DO CONTEÚDO POLÍMEROS SINTÉTICOS A PARTIR DA TEMÁTICA LIXO E RECICLAGEM NAS AULAS DE QUÍMICA DO ENSINO MÉDIO: UMA PROPOSTA DIDÁTICA
}

\author{
Denise Fernanda Tudes Mury ${ }^{1}$, Leonardo Baltazar Cantanhede ${ }^{1}$, \\ SEVERina CoÊlho da Silva Cantanhede ${ }^{2}$ \\ ${ }^{1}$ Instituto Federal de Educação, Ciência e Tecnologia do Maranhão, Campus de Codó \\ ${ }^{2}$ Universidade Federal do Maranhão, Campus de Codó \\ $<$ fernandamury@live.com>.<leonardo.cantanhede@ifma.edu.br> \\ $<$ severina.cantanhede@ufma.br>
}

DOI: $10.21439 /$ conexoes.v9i4.861

\begin{abstract}
Resumo. A educação ambiental pode ser entendida como prática socioeducativa integrada, contínua e permanente, devendo ser trabalhada com o propósito de informar a sociedade sobre a importância de amenizar os problemas relacionados ao meio ambiente. A reciclagem surge então como uma prática que pode contribuir para resolução de alguns problemas causados pelo excesso de lixo. Assim, é atribuído à escola parte da responsabilidade em difundir as práticas da educação ambiental que devem estar voltadas para a formação de cidadãos que valorizam o meio ambiente, contribuindo para que os impactos ambientais causados, principalmente pelo lixo, tornem-se menores. Neste trabalho, apresentamos uma proposta, a partir da temática lixo e reciclagem, para uma aula de Química do terceiro ano do ensino médio utilizando o conteúdo polímeros sintéticos. Para sua execução elaboramos um plano e roteiro de aula destinado ao professor que fizer a opção por sua utilização em seu ambiente de ensino.
\end{abstract}

Palavras-chaves: Educação Ambiental, Ensino de Química, Polímeros Sintéticos.

\begin{abstract}
Environmental education can be understood as an integrated social and educational practice, continuous and permanent, and must be worked in order to inform the society about the importance of ease the problems related to the environment. Recycling then emerges as a practice that can contribute to solving some problems caused by excessive garbage. So, is attributed to the school of the responsibility to disseminate the practices of environmental education should be directed to the formation of citizens who value the environment, contributing to the environmental impacts caused mainly by garbage become less impacting. In this work, we present a proposal from the theme garbage and recycling for a chemistry class the third year of high school using content synthetic polymers. For its implementation we developed a plan and class script for the teacher who makes the choice for use in your learning environment.
\end{abstract}

Keywords: Environmental Education, Teaching of Chemistry, Synthetic Polymers.

\section{INTRODUÇÃO}

Atualmente, muito se tem discutido sobre os problemas ambientais referentes à preservação do meio ambiente e do mau uso de recursos naturais (SANTOS; JACOBI 2011; JACOBI, 2003). Sobre esse aspecto, destacamos a poluição causada pelo descarte inadequado de resíduos sólidos e orgânicos, o que ocasiona uma enorme quantidade de lixo. Essa prática tem sido considerada como propulsora de impactos negativos para o meio ambiente (SANTOS; NETO; SOUSA, 2014, SOUZA;

\section{SANTOS; JÚNIOR 2011).}

No Brasil, de acordo com as estimativas, cada pessoa produz, aproximadamente, um quilograma (1 Kg) de lixo por dia, o que corresponde a 230 mil toneladas de lixo orgânico e embalagens variadas, entre outros resíduos, gerados diariamente (SILVA et al., 2011). Considerando o material descartado, $76 \%$ é destinado a locais impróprios, contribuindo assim para a proliferação de vetores de inúmeras patologias. Como resultado deste descarte, a matéria orgânica entra em processo de 

QUÍMICA DO ENSINO MÉDIO: UMA PROPOSTA DIDÁTICA

decomposição e forma uma mistura complexa de vários gases (metano, dióxido de carbono, gás sulfídrico e amônia, entre outros ácidos orgânicos voláteis) considerados prejudiciais à saúde humana, pois quando em contato com o sistema respiratório podem causar lesões irreversíveis, levando o indivíduo a óbito. Destaca-se ainda, a contaminação dos recursos hídricos com o chorume (líquido escuro) que faz parte do processo de decomposição do lixo (FADINI; FADINI, 2001).

Neste contexto, com a pretensão de amenizar as ações humanas relacionadas à poluição do meio ambiente, são necessárias algumas ações voltadas para a valorização da educação ambiental, pois tais iniciativas podem contribuir para a formação de uma consciência crítica sobre a problemática socioambiental (MASSENA; MARINHO, 2011). Tal prática busca favorecer uma abordagem pedagógica voltada para o esclarecimento e conscientização ambiental, mudança de comportamento, além de desenvolver no educando competências e habilidades que propiciem a capacidade de avaliação, participação mais ativa e tomada de decisão diante das questões relacionadas ao meio ambiente (JACOBI, 2003).

A educação ambiental, assim como outras áreas do conhecimento, é um processo intelectual de aprendizagem social, que tem como base o diálogo, a interação de informações, conceitos e significados que podem proporcionar uma aprendizagem mais significativa em sala de aula, principalmente quando associada à experiência pessoal de cada estudante (JACOBI, 2003). Os Parâmetros Curriculares Nacionais (PCN) de Meio Ambiente (BRASIL, 1998), destacam as vantagens de se trabalhar a educação ambiental em sala de aula ao citar que:

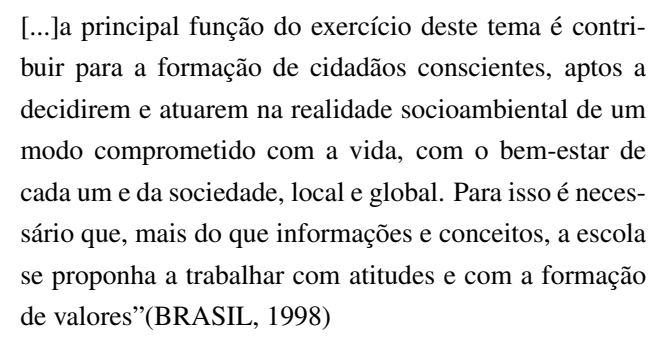

Diante desse contexto, é relevante destacar a necessidade dos professores trabalharem a temática ambiental, como tentativa de resgatar e construir novos saberes que contribuam para o desenvolvimento de valores como: confiança, respeito mútuo, responsabilidade social, compromisso e solidariedade (BONOTTO; SEMPREBONE, 2010). Nessa perspectiva, situamos a educação ambiental em um contexto mais amplo, que representa um dos caminhos da educação para a cidadania (JACOBI, 2003). Nesses termos, associar esse modelo de educação com a abordagem dos conteúdos químicos é fortalecer que o ensino da Química, assim como das demais ciências, requer uma ação pedagógica voltada para o desenvolvimento intelectual do aluno, buscando aprimorar uma visão mais crítica da sua realidade. Dessa forma, a Química, por meio da educação ambiental, pode ser considerada como um instrumento que contribui no processo de ensino e aprendizagem, valoriza as diversas formas de conhecimento e possibilita a formação para a cidadania (SANTOS; JACOBI. 2011, JACOBI, 2003).

Quanto aos conteúdos da Química, vários conceitos podem ser trabalhados sob essa temática, tais como: poluição ambiental, meio ambiente, o lixo e seus impactos ambientais e sociais, qualidade de vida, desenvolvimento sustentável, saúde, cidadania, práticas de educação ambiental etc. A partir de tais temas tornase possível abordar a problemática ambiental que, aliada ao ensino da Química pode favorecer ao estudante a compreensão tanto dos processos químicos presentes na matriz curricular de Química para o ensino médio quanto suas implicações ambientais, sociais, políticas e econômicas. Além disso, considerando o ponto de vista pedagógico, ensinar conceitos químicos de forma contextualizada e sob a perspectiva de temas ambientais, como lixo e poluição, pode esclarecer dúvidas e gerar novos conhecimentos sobre o conteúdo proposto, permitindo ao estudante fazer relações com o seu cotidiano, o que possibilita melhor entendimento e criticidade sobre os problemas socioambientais (SANTOS; SCHNETZLER, 2003).

Nesse contexto, o estudo do conteúdo polímeros pode ser abordado em virtude dessa classe de compostos apresentar propriedades diversificadas, o que possibilita sua aplicação na fabricação de uma ampla variedade de produtos de grande utilidade em nossa sociedade (SOUZA et al., 2011). Tanto polímeros naturais (encontrados na natureza, tais como, borracha - extraída da seringueira, celulose, proteínas e polissacarídeos) quanto os polímeros sintéticos (produzidos artificialmente, como poliamidas, poliésteres e polietileno) estão presentes na sociedade moderna,entretanto, seu descarte inadequado, longo período de decomposição no meio ambiente e até mesmo o impacto socioambiental que esse tipo de material pode causar às gerações futuras justificam a discussão desta temática no âmbito educacional do ensino da química (SANTOS et al. 2012).

Uma saída economicamente viável e ecologicamente correta para minimizar esses problemas é reduzir a utilização desses produtos poliméricos ou reutilizálos. A reciclagem então surge como uma alternativa 
viável que pode minimizar alguns dos desafios relacionados à poluição ambiental e suas consequências para a sociedade contemporânea, sendo a Química uma boa aliada nesse processo (FADINI; FADINI, 2001). Logo, o objetivo deste trabalho é propor a inclusão da temática, lixo e reciclagem nas aulas de química da $3^{\text {a }}$ série do ensino médio, relacionando este tema com o conteúdo, polímeros sintéticos. Como hipótese inicial pretende-se que os estudantes consigam, com esta estratégia didática: assumir um comportamento ativo e crítico ao se discutir os problemas ambientais causados pela grande quantidade de lixo depositado no meio ambiente; e buscar soluções para diminuição do seu descarte indiscriminado, atentando para as condições básicas e necessárias para o bem-estar da sua vida, de seus familiares e de toda a comunidade. Pretende-se ainda, disponibilizar ao professor da educação básica um suporte pedagógico para a discussão da educação ambiental nas aulas de química do ensino médio.

\section{LEVANTAMENTO BIBLIOGRÁFICO}

\subsection{O Ensino da química no nível médio}

Segundo as Diretrizes Curriculares Nacionais para o Ensino Médio, que organiza as áreas de conhecimento e orienta a educação nacional, o principal objetivo da aprendizagem nas áreas das Ciências Naturais é o desenvolvimento de valores como sensibilidade, solidariedade etc., atributos considerados necessários para a formação da cidadania. Além disso, ainda sinaliza para a forma como o aprendizado de Ciências, iniciado no Ensino Fundamental, deve ser complementado e aprofundado no Ensino Médio. Nessa etapa da educação básica, os objetivos educacionais para a formação dos estudantes podem ser planejados considerando os procedimentos e atitudes envolvidas, assim como suas habilidades, competências e valores adquiridos (BRASIL 2002).

Nesses termos, como parte integrante da área das Ciências da Natureza, o aprendizado da Química no nível médio deve conduzir os estudantes para a compreensão das transformações químicas que ocorrem no mundo físico, de forma abrangente e integrada, para que sejam capazes de julgar com fundamentos científicos as informações provenientes das tradições culturais, da mídia e da própria escola, além de se posicionar de forma independente, enquanto indivíduo e cidadão social. Tal aprendizagem deve permitir ao aluno a compreensão tanto dos processos químicos em si, quanto da construção do conhecimento científico inerente às aplicações tecnológicas e seus resultados ambientais, sociais, políticos e econômicos (BRASIL, 2002). Dessa forma, o ensino da Química, que tem como um de seus objetivos contribuir para a formação da cidadania, deve propiciar, também o desenvolvimento de conhecimentos e valores que possam direcionar o educando para a prática de ações que proporcionem uma melhor interação do indivíduo com a sociedade na qual está inserido. Além disso, o estudo da Química pode possibilitar que o estudante identifique como utilizar e manipular certas substâncias, compreender a composição de determinados produtos industrializados, reconhecer as consequências dos produtos químicos no meio ambiente, e o mais importante, perceber o papel da Química e da ciência na sociedade (SANTOS; MORTIMER, 2000, SANTOS; SCHNETZLER, 2003).

No entanto, um número significativo de alunos demonstram dificuldades no aprendizado dessa disciplina, pois não conseguem perceber o sentido ou a relevância do que estão estudando. Isso porque geralmente os conteúdos são apresentados de forma descontextualizada, o que dificulta a compreensão de seus significados, contribuindo para a falta de interesse dos estudantes pela área da Química (PONTES et al., 2008). Assim, como forma de amenizar tal fato, o professor pode conduzir sua aula de maneira que o estudante consiga associar os assuntos químicos estudados em sala de aula com os fatos observados no seu dia a dia. Essa prática pode atribuir sentido ao tema desenvolvido, pois faz uma associação dos assuntos apresentados com as situações vivenciadas no seu cotidiano. Como exemplo, podemos considerar o lixo e a crescente degradação ambiental, divulgada pelos meios de comunicação (MACHADO; MORTIMER, 2007).

\subsection{Conteúdos programáticos para o ensino da química}

Os Parâmetros Curriculares Nacionais para o Ensino Médio, relacionados à área de Ciências da Natureza sugerem que, no decorrer do processo de ensino e aprendizagem, o ensino não seja desenvolvido a partir de uma interação artificial entre o conhecimento químico e o cotidiano do aluno, limitando-se a exemplos apresentados apenas de forma ilustrativa, ao final das aulas. A proposta é partir de situações-problema reais que favoreçam a busca de conhecimentos e que possibilitem a sua compreensão e resolução (BRASIL, 2002). Nesses termos, as questões ambientais, como os problemas relacionados à poluição causada pelo excesso de lixo, e a reciclagem como alternativa viável para amenizar este problema, são temas que podem ser desenvolvidos a partir de alguns dos conteúdos programáticos da disciplina de Química. Assim sendo, um dos objetivos da aula, ao utilizar uma abordagem contextualizada da te- 
ABORDAGEM DO CONTEÚDO POLÍMEROS SINTÉTICOS A PARTIR DA TEMÁTICA LIXO E RECICLAGEM NAS AULAS DE QUÍMICA DO ENSINO MÉDIO: UMA PROPOSTA DIDÁTICA

mática lixo, é proporcionar para o estudante a compreensão das relações existentes entre o lixo, sua produção excessiva e as consequências ambientais, além de desenvolver os conceitos químicos como propriedades e transformações da matéria, relacionados com a temática em questão (OLIVEIRA; RECENA, 2014). Assim, à medida que a problemática relacionada ao lixo é tratada no ambiente do ensino da Química, viabiliza-se para o estudante a oportunidade de desenvolver competências tais como: compreensão da composição e estruturação dos materiais que ele utiliza no seu dia a dia; reconhecimento de aspectos relevantes do conhecimento químico e suas tecnologias; avaliação da ciência e tecnologia química sob o ponto de vista ético, como forma de exercer a sua cidadania com responsabilidade, integridade e respeito; desenvolvimento de atitudes e valores compromissados com os ideais de cidadania voltados para ações que valorizem a preservação ambiental (BRASIL, 2006).

\subsection{Desenvolvimento sustentável/reciclagem}

A forma que melhor define o desenvolvimento sustentável é através de práticas que reforcem as relações necessárias entre economia, tecnologia, sociedade e política. Além disso, também chama-se atenção para necessidade de uma nova postura ética com relação à preservação do meio ambiente, caracterizada pelo desafio de se responsabilizar tanto pelas gerações futuras, quanto pela sociedade contemporânea (SANTOS 2007). Nessa perspectiva, em meio aos problemas relacionados com os impactos negativos causados ao meio ambiente, a reciclagem de materiais, até então destinados ao lixo, surge como uma possível alternativa de amenizar parte dessa problemática, visto que trata os materiais por meio de processos químicos industriais, proporcionando para estes uma nova utilidade. Tal alternativa evita que produtos sejam descartados na natureza (EIGENHEER; FERREIRA; ADLER, 2005).

Podemos destacar dois grandes acontecimentos que marcaram significativamente essa iniciativa: a Conferência das Nações Unidas sobre o meio Ambiente e desenvolvimento, (também conhecida como ECO 92), na qual vários países debateram sobre alternativas viáveis para direcionar o planeta à prosperidade econômica, de forma que fosse possível causar menos destruição ambiental e desigualdade social, a partir de mudanças nos padrões de produção e consumo, e o resultado dessa Conferência com a criação de um documento designado como Agenda 21, na qual se tornou possível reunir ações que poderiam ser adotadas em cada país, incluindo a gestão do lixo como tema prioritário (CEMPRE, 2013).
Nesse contexto, a prática da reciclagem surge como uma possibilidade benéfica caracterizada como uma atividade sustentável, visto que fica evidente a sua importância em termos ambientais, sociais e econômicos. Isso porque a reciclagem ainda evita a presença excessiva da quantidade de resíduos sólidos nas ruas, aterros sanitários e lixões, reduz a quantidade de matéria-prima virgem utilizada nas indústrias para a fabricação de materiais, gera empregos nas indústrias de reciclagem e cooperativas de catadores de materiais recicláveis, diminuindo assim a poluição do solo e amenizando os prejuízos causados à saúde pública decorrentes desse tipo de poluição (CANELOI, 2010). Em termos de desenvolvimento sustentável a prática da reciclagem se apresenta como ambientalmente correta, socialmente justa e economicamente viável (SANTOS et al., 2012). No entanto, a reciclagem não deve ser observada como a principal fonte para a solução dos problemas relacionados ao lixo, pois, embora seja vista como uma atividade econômica, ela deve ser entendida também como um elemento dentro de um conjunto de soluções (FADINI; FADINI, 2001).

Nos últimos anos, várias escolas brasileiras têm aderido à prática do modelo de sustentabilidade. Desse modo, passaram a ensinar para os alunos a importância dos recursos naturais do planeta, principalmente por serem finitos, além de orientar que seu uso indiscriminado compromete a sobrevivência humana, despertando sobre a necessidade de implementação de estratégias que atendam à conservação ambiental (VASCONCELLOS et al. 2009). Nesse sentido, é atribuída à educação escolar a função de buscar métodos e ações voltadas para a conservação da biodiversidade e do desenvolvimento sustentável. Assim, é designado um novo papel para o espaço escolar: buscar desenvolver nos estudantes valores e atitudes, fundamentados em temas sociais, principalmente porque suas ações repercutem em diferentes esferas da sociedade (FONSECA, 2007), (SWAMINATHAN, 1992). Diante de tal contexto, o presente trabalho se justifica pela proposta de utilizar a temática lixo e reciclagem como um assunto que pode despertar e motivar o interesse dos estudantes do ensino médio com relação aos problemas ambientais, possibilitando assim, uma postura crítica a respeito desse tema. A proposta está direcionada para o terceiro ano do ensino médio, a partir do conteúdo polímeros sintéticos.

\section{METODOLOGIA}

\subsection{Pesquisas nacionais sobre educação ambien- tal, lixo e reciclagem}

Para realizar o levantamento bibliográfico sobre os temas educação ambiental, lixo e reciclagem, foram rea- 
lizadas buscas em arquivos de periódicos no portal Scielo e no portal Capes e também foram investigados artigos publicados nos últimos sete anos (2009 a 2015), em revistas como a Revista Química Nova na Escola (QNEsc) e a Revista Brasileira de Pesquisa e Educação em Ciências. Artigos publicados há mais tempo também foram utilizados devido à sua grande relevância científica. Foram referenciados 30 artigos que abordaram a importância da educação ambiental e os impactos negativos que o ambiente sofre pela poluição do lixo. Alguns trabalhos buscaram relacionar as questões ambientais com uma formação educacional voltada para a cidadania, realizando a abordagem dessas temáticas em aulas de Ciências e de Química. A maioria dos trabalhos descritos nos artigos foi realizada com alunos e professores de escolas do Ensino Fundamental e Médio, mas alguns trabalhos também incluíram alunos de graduação e empresas.

\subsection{Abordagem da temática lixo e reciclagem nos conteúdos de química do ensino médio}

A abordagem da temática lixo e reciclagem é uma proposta que visa à associação entre os conteúdos químicos, estudados na $3^{\text {a }}$ série do ensino médio e as questões cotidianas relacionadas ao meio ambiente. O planejamento das aulas que incluem a abordagem dessa temática para o conteúdo polímeros sintéticos - polímeros de adição (teflon, PVC, polietileno etc.); condensação (poliéster, silicone, poliamidas etc.) e copolímeros (borracha sintética) - foi realizado a partir de pesquisa acerca das relações existentes entre o conteúdo químico e a temática ambiental a ser abordada e discutida na aula. A fundamentação teórica foi obtida em livros didáticos de química utilizados no ensino médio e no portal da revista QNEsc. A proposta da abordagem da temática será realizada nas aulas logo após a explanação dos conceitos trabalhados dentro do assunto polímeros sintéticos.

\subsection{Plano e Roteiro de aula}

Para organizar a condução das aulas, foram elaborados um plano e um roteiro de aula. No plano de aula estão descritos os objetivos que se deseja alcançar na aula, os conteúdos trabalhados, a metodologia para o desenvolvimento do tema, os recursos didáticos que serão utilizados e a forma de avaliação a ser realizada pelo professor. Já o roteiro foi proposto para que o professor possa desenvolver o seu trabalho da forma mais eficiente possível em termos de tempo, procurando utilizar todas as ferramentas didáticas propostas para a execução da aula.

\section{RESULTADOS E DISCUSSÃO}

\subsection{Pesquisas nacionais sobre educação ambien- tal, lixo e reciclagem}

Observou-se durante o levantamento bibliográfico que é vasta a natureza de trabalhos e pesquisas que procuram incorporar as questões ambientais nas aulas de ciências, tanto do ensino fundamental (VALENTIN; SANTANA, 2010) quanto do ensino médio (FARIAS; CARVALHO, 2007). Algumas pesquisas que foram descritas mostram trabalhos aplicados em turmas de graduação dos cursos de licenciatura (FABRIS; NETO; TOALDO, 2010) e algumas direcionadas especificamente para formar o professor que atua diretamente com questões ambientais em sala de aula (SANTOS; JACOBI. 2011, JACOBI, 2003). Esse levantamento bibliográfico foi importante, pois serviu de embasamento científico para a compreensão dos conceitos, atividades e procedimentos metodológicos já existentes na literatura, acerca de como algumas problemáticas ambientais são tratadas nas instituições de educação, seja ela de nível médio ou superior.

As questões ambientais são de grande interesse para toda a sociedade e um lugar bem específico para tratálas é a sala de aula. No entanto, existe certa limitação no que se refere à abordagem dessa temática, pois alguns professores não a utilizam, com a justificativa de que elas extrapolam o tempo de aula e, portanto, atrapalham o desenvolvimento do conteúdo programático (WATANABE-CARAMELLO; STRIEDER; GEHLEN 2012). Esse fato pode contribuir para a falta de postura cidadã quando os alunos são questionados a proporem soluções em situações-problema que envolvam suas vidas e o meio ambiente. Uma das funções sociais do ensino básico é desenvolver o indivíduo para o pleno exercício da cidadania, por esta razão, os alunos precisam ser auxiliados a tomar consciência da sua realidade e da sua capacidade em transformá-la (NETO; KAWASAKI, 2015).

$\mathrm{Na}$ literatura encontramos trabalhos que apresentam resultados de atividades desenvolvidas na educação básica, que tratam do tema educação ambiental. Goi e Santos (2009) e Santos e Schnetzler (2003) desenvolveram um estudo com alunos da segunda série do ensino médio, cujo tema central foram as reações de combustão e o impacto ambiental que causam. Nessa pesquisa qualitativa, os autores procederam com o acompanhamento e a análise de atividades experimentais dentro do laboratório de química, aplicando uma metodologia que visa à resolução de problemas ambientais. Associando estratégias teóricas às estratégias práticas, os alunos propuseram resoluções para problemas como gases poluidores; alternativas para a diminuição dos proble- 

QUÍMICA DO ENSINO MÉDIO: UMA PROPOSTA DIDÁTICA

mas ambientais; reciclagem do lixo; filtros nas chaminés para diminuir a poluição; uso da energia solar, eólica e de biocombustíveis; reciclagem de materiais, dentre outros. Os autores ressaltam que os alunos parecem ter adquirido autonomia e segurança em relação aos aspectos conceituais dos problemas propostos, revelando a aprendizagem de novos conhecimentos, procedimentos e atitudes.

\subsection{Abordagem da temática 'lixo e reciclagem' nos conteúdos de química do ensino médio}

A partir da leitura dos trabalhos que abordaram a temática educação ambiental, foi proposta uma abordagem dessa temática com a perspectiva de se trabalhar conteúdos de Química da $3^{\mathrm{a}}$ série do ensino médio a partir das questões cotidianas relacionadas ao meio ambiente. Logo, para melhor organizar e conduzir a aula, foram elaborados o plano e o roteiro de aula para o conteúdo intitulado polímeros sintéticos. Assim sendo, apresentamos inicialmente na Figura 1 o organograma elaborado para representar, simplificadamente, a estruturação da aula de Química para o conteúdo polímeros sintéticos que será ministrado pelo professor. Esse conteúdo permite fazer uma abordagem sobre os problemas ambientais ocasionados pela quantidade excessiva de produtos plásticos presentes no lixo, além de ressaltar a reciclagem como uma alternativa sustentável e econômica.

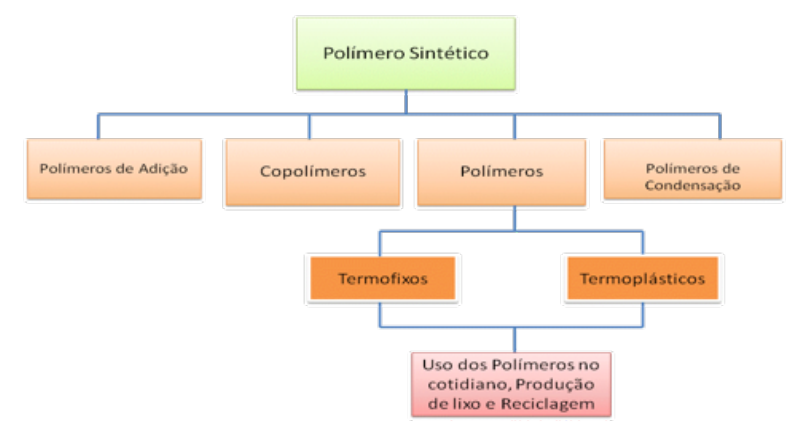

Figura 1: Organograma da aula Polímeros Sintéticos, estruturada a partir da temática Lixo, seu impacto ambiental e Reciclagem. Fonte: Elaborada pelos autores

\subsection{Plano e Roteiro de aula}

A partir da estruturação dos conteúdos a serem trabalhados, disponibilizamos uma proposta de roteiro de aula, para que o professor possa potencializar o desenvolvimento do seu trabalho, em termos de tempo, utilizando alguns recursos didáticos e metodológicos que podem melhorar a aprendizagem durante a condução da aula.
Na Figura 2, apresentamos o roteiro da aula distribuído em quatro etapas fundamentais para o desenvolvimento da temática lixo e reciclagem, a partir dos objetivos propostos para essa abordagem.

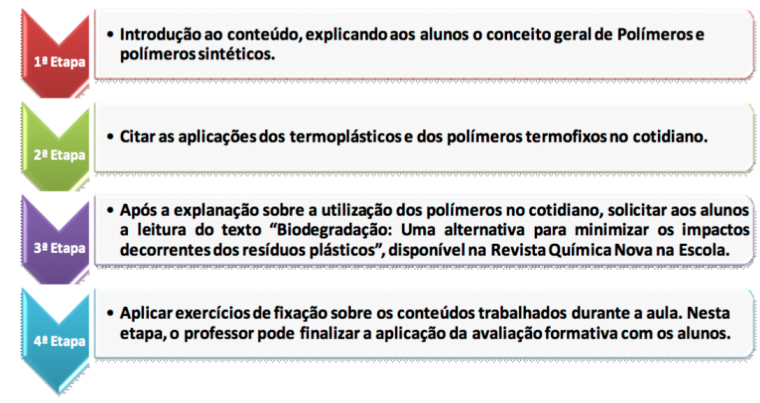

Figura 2: Roteiro de aula para a abordagem da temática, Lixo, seu impacto ambiental e Reciclagem, na aula de Polímeros Sintéticos. Fonte: Elaborada pelos autores

Na primeira etapa, com duração de quarenta minutos (40 min), o professor poderá começar a aula conceituando polímeros e explicando quais os diferentes tipos de polímeros sintéticos existentes atualmente e que são classificados em polímeros de adição, copolímeros e polímeros de condensação. É importante ressaltar que os polímeros são compostos químicos de elevada massa molecular, resultantes de reações químicas denominadas, reações de polimerização. Explicitar ainda, as aplicações desses compostos no cotidiano, citando os plásticos, também denominados de polímeros sintéticos, como um tipo material corriqueiramente presente no lixo doméstico e industrial (MICHAELI et al., 1995), além de mostrar as suas diferenças estruturais, assim como sua classificação em termoplásticos e termofixos. Para atingir o objetivo específico, associar o conteúdo polímeros sintéticos, com a abordagem de temas relacionados ao lixo e a reciclagem. O professor poderá utilizar as questões envolvidas com a poluição ambiental causada pela grande quantidade de objetos plásticos presentes no lixo, destacando a reciclagem como uma alternativa que pode amenizar esse quadro.

Na segunda etapa, com duração de dez minutos (10 min), o professor irá realizar uma abordagem contextualizada dos termoplásticos e termofixos, enfatizando as diferentes aplicações no dia a dia da sociedade, devido às vantagens que apresentam como a durabilidade e a resistência à ação do ar. Entretanto, é fundamental mencionar que em meio a tantas vantagens, existem as desvantagens, principalmente, quando os polímeros são descartados na natureza, pois, a sua resistência faz com que permaneçam no meio ambiente, sem se degrada- 
ABORDAGEM DO CONTEÚDO POLÍMEROS SINTÉTICOS A PARTIR DA TEMÁTICA LIXO E RECICLAGEM NAS AULAS DE QUÍMICA DO ENSINO MÉDIO: UMA PROPOSTA DIDÁTICA

rem, durante décadas e até mesmo séculos, aumentando a problemática ambiental causada pelo lixo (SANTOS et al. 2012).

$\mathrm{Na}$ terceira etapa, após as discussões sobre a utilização dos diferentes tipos de polímeros no cotidiano, os alunos de posse do texto "Biodegradação: Uma alternativa para minimizar os impactos decorrentes dos resíduos plásticos", disponível na revista QNEsc (CANGEMI; SANTOS; CLARO, 2005), farão uma leitura criteriosa, buscando aspectos relevantes sobre o conteúdo polímeros sintéticos apresentado no texto, tais como: definições, importância, aplicações e a reciclagem, como uma alternativa para a resolução dos problemas ambientais ocasionados pelos plásticos. Nesta etapa, o professor poderá citar a utilização de polímeros biodegradáveis como medida viável para amenizar parte dos problemas causados pelo excesso de resíduos plásticos. Cabe ao professor enfatizar também que os plásticos biodegradáveis apresentam na sua estrutura biopolímeros, o que possibilita menor tempo de decomposição do material, causando assim, menos danos ao meio ambiente (SANTOS et al. 2012), além de discutir outras medidas consideradas eficazes, no sentido de tentarmos diminuir o uso de produtos confeccionados a partir de plástico, como as ecobags (sacolas ecológicas), construídas de algodão, outro material resistente que pode perfeitamente substituir as sacolas plásticas (GREENSENSE, 2014). Esta etapa terá duração de quarenta minutos (40 min). Na quarta e última etapa, com duração de dez minutos (10 min), o professor irá aplicar exercícios com questões discursivas para a fixação dos conteúdos trabalhados durante a aula, como por exemplo: "O polietileno, apesar do impacto negativo sobre o meio ambiente, é um dos plásticos mais utilizados no mundo. Com base nessa informação, comente sobre os problemas ambientais decorrentes de sua utilização na sociedade, a partir de suas características químicas, já estudas". Nesta etapa, o professor pode finalizar com a aplicação da avaliação formativa.

O tema Reciclagem, que é sugerido como uma possível solução para amenizar parte dos impactos causados à natureza em decorrência do excesso de lixo, deve ser apresentado ao aluno como uma prática social que faz parte da comunidade em que ele se encontra inserido. Em algumas cidades do interior de muitos estados do Brasil, como exemplo, a cidade de Codó, situada no Maranhão, a prática da reciclagem é vista como uma forma de sobrevivência. Embora em muitas dessas regiões não existam indústrias de reciclagem, os moradores organizam "postos" de coleta para o recebimento de materiais como metal, vidro, plástico e papel, como apresentado na Figura 3.

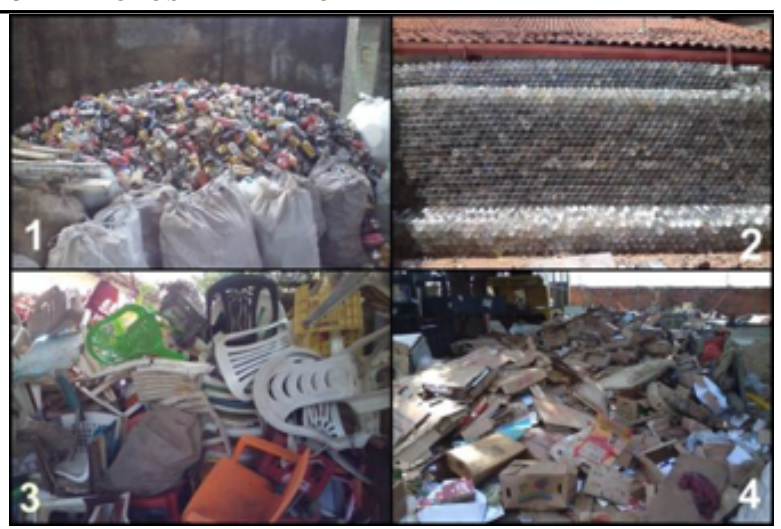

Figura 3: Materiais recicláveis recolhidos em postos de coleta na cidade de Codó - MA: 1) alumínio; 2) vidro; 3) plástico; 4) papel. Fonte: Arquivo pessoal

Assim, trabalhar o ensino da Química utilizando temas geradores pode ser considerado uma estratégia no processo de conscientização da realidade atual da sociedade, constituindo-se um ponto de partida para o desenvolvimento de cidadãos mais críticos e participativos. Apartir da educação ambiental, o estudante poderá adquirir atitudes pautadas em uma conscientização política e formação ética voltada para a responsabilidade social e com o planeta (DICKMANN; CARNEIRO 2012). Dessa forma, torna-se claro e evidente a necessidade de superar a transmissão pura e simples do conteúdo, de forma mecânica e vazia de significados concretos. Consequentemente, trabalhar a educação na perspectiva de temas geradores pode possibilitar a formação crítica e dá significado ao ensino-aprendizagem (FREIRE, 1980). Nessa perspectiva, consideramos ser possível incluir nas aulas de Química temas como lixo e reciclagem (temas geradores), a partir dos conteúdos curriculares do ensino médio. Assim, os temas geradores podem proporcionar aos estudantes a apropriação de saberes referentes aos conteúdos científicos da disciplina quando trabalhados de forma contextualizada, como também contribuir com a observância aos acontecimentos diários da vida social. Quanto à contextualização de tais temas, entendemos que seja um caminho que pode orientar a formação de cidadãos aptos ao exercício da cidadania, capazes de intervir ativamente no ambiente social no qual estão inseridos, sob uma visão crítica da realidade em seus espaços históricos, sociais, políticos e econômicos (RESSETTI, 2000).

Considerando a relevância da temática para a formação dos estudantes, foi elaborado o plano de aula, como já mencionado, como forma de contribuir com o trabalho do professor. O plano de aula é uma importante 

QUÍMICA DO ENSINO MÉDIO: UMA PROPOSTA DIDÁTICA

ferramenta metodológica utilizada para organizar e subsidiar o trabalho docente. Nessa proposta, definimos os objetivos almejados considerando a temática ambiental, os conteúdos químicos, a metodologia e a forma de avaliação. Na Tabela 1 dispomos a estruturação do plano sugerido.

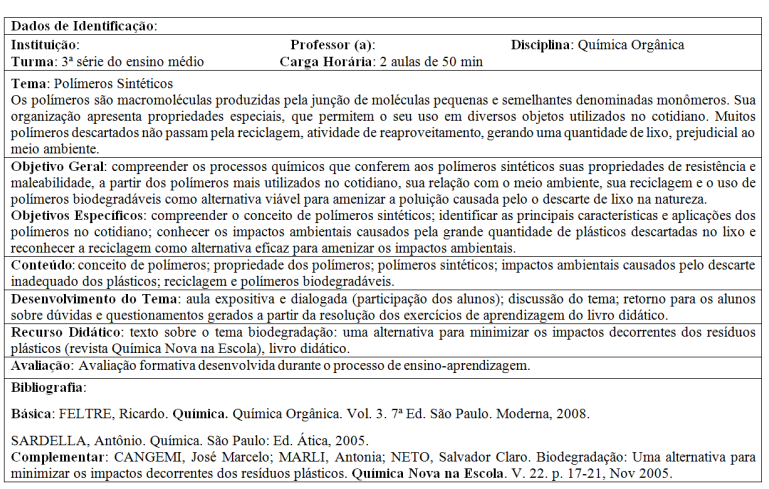

Figura 4: Proposta de plano a ser trabalhado em uma aula de Química da $3^{\mathrm{a}}$ série do ensino médio sobre o conteúdo polímeros sintéticos a partir da temática ambiental.

A estruturação do plano de aula é importante por ser considerado uma sequência que vai orientar o desenvolvimento das aulas nos dias letivos. É a sistematização de todas as atividades planejadas e aplicadas na dinâmica do ensino-aprendizagem. Nesse sentido, a ação de planejar o que será ministrado no ambiente escolar deve seguir, essencialmente, preceitos científicos, propriedade dos conhecimentos químicos e metodologias de ensino adequadas, considerados meios eficientes na obtenção de resultados positivos (PILETTI, 2001). Para essa proposta, com a finalidade de obter os objetivos destacados, ao planejar e aplicar a estratégia de ensino, a temática ambiental deverá estar em consonância com o conteúdo químico, permitindo assim a possibilidade de melhor compreender as consequências para a saúde humana e para o meio ambiente causadas pela poluição de plásticos descartados indevidamente no lixo (CANGEMI; SANTOS; CLARO, 2005). Além disso, é relevante ressaltar as várias possibilidades existentes e disponíveis para os professores (recursos didáticos como jogos, textos de divulgação científica, internet etc.) que podem contribuir como forma de atrair a atenção do aluno para o conteúdo, favorecendo uma aprendizagem mais significativa (LUCKESI, 2001).

Para consolidar o planejamento do trabalho a ser desenvolvido, também é necessária uma forma coerente de avaliação, no sentido de que seja possível verificar o grau de assimilação dos estudantes diante do conteúdo proposto. Nesses termos, a avaliação deve ser entendida como um elemento de integração e motivação no processo de ensino. Uma alternativa é a avaliação formativa, pois ajuda o aluno a aprender e se desenvolver melhor no ambiente escolar. Esse tipo de avaliação é uma prática contínua que favorece a aprendizagem, contribuindo para melhor acompanhamento e orientação dos estudantes durante o seu processo de formação. Além disso, permite ao docente realizar alterações no decorrer do processo, adaptando as formas de ensino às necessidades dos estudantes (PERRENOUD; THURLER 2002).

Entendemos que o planejamento da aula é uma tarefa cotidiana de estruturação das atividades a serem desenvolvidas no ambiente escolar, o que demanda tempo, devido a ser uma etapa relevante para o êxito do trabalho do profissional da educação. Isso porque faz parte da competência teórica do professor e dos compromissos com a democratização do ensino (FUSARI, 1990). Assim, é importante para a prática pedagógica do professor, como organizador e norteador do seu trabalho. Nesse caso, o planejamento permite que se observe a dimensão da relevância de sua prática docente e os objetivos a que se destina (CASTRO; TUCUNDUVA; ARNS, 2008). Considerando então a importância do planejamento das atividades desenvolvidas em sala de aula, utilizamos além do livro didático, um texto da revista QNEsc (CANGEMI; SANTOS; CLARO, 2005) como recurso para complementação e discussão do conteúdo. Escolhemos esse texto por apresentar potencialidade, pois discute a reciclagem de polímeros biodegradáveis como uma opção para amenizar parte dos impactos causados pela poluição gerada pelo homem, a partir do descarte de utensílios plásticos na natureza. O texto ainda aborda o conceito e tipos de plásticos, como também a sua importância para o cotidiano da sociedade contemporânea, o que favorece a compreensão do processo químico de biodegradação dos plásticos no meio ambiente.

Embora os livros didáticos já apresentem informação textual relevante a respeito dos temas trabalhados nas aulas, a utilização de textos é defendida como apoio ao trabalho do professor, pois esse recurso didático pode proporcionar aos estudantes o acesso a informações atualizadas sobre ciência e tecnologia, em uma linguagem contextualizada, flexível e próxima do cotidiano, permitindo o conhecimento de novos significados. A utilização de tais textos também é justificada pela possibilidade de se aprimorar os conceitos, a leitura e escrita. Nesse sentido, os textos se tornam uma alternativa para aqueles docentes que ainda utilizam apenas o livro didático como material de leitura em suas aulas. Dessa forma, os textos podem estimular as discussões e 
ABORDAGEM DO CONTEÚDO POLÍMEROS SINTÉTICOS A PARTIR DA TEMÁTICA LIXO E RECICLAGEM NAS AULAS DE QUÍMICA DO ENSINO MÉDIO: UMA PROPOSTA DIDÁTICA

a participação dos estudantes em sala de aula (CANTANHEDE, 2012).

\section{CONCLUSÕES E CONSIDERAÇÕES FINAIS}

A proposta de inclusão da temática lixo e reciclagem nas aulas de Química da educação básica foi pensada com o objetivo de se buscar a associação do conteúdo polímeros sintéticos com os problemas causados pelo excesso de lixo descartado no meio ambiente. Quando buscamos trabalhar temas dessa natureza no ambiente de sala de aula, oportunizamos, tanto para o professor quanto para o estudante, a possibilidade de reflexão sobre ações e práticas que podem causar danos à natureza. Além disso, o tema lixo e reciclagem, abordado no ensino da Química, pode tornar as aulas mais atraentes e menos cansativas, o que pode favorecera participação ativa, o posicionamento crítico e a proposição de soluções para questões relacionadas com a excessiva quantidade de lixo descartada diariamente no meio ambiente. Nesse contexto, acreditamos que o ensino de conteúdos químicos, realizado através de temas que envolvam a problemática ambiental e que conduzam os estudantes a criarem alternativas para a resolução de problemas, se apresenta como uma proposta factível, uma vez que o estudo de questões ambientais direciona para uma reflexão de práticas responsáveis e sustentáveis como alternativa para melhor preservação da natureza. Assim, através da educação ambiental, os estudantes podem ser orientados para a prática e valorização de ações benéficas para um meio ambiente sustentável, assim como para todos os seres vivos dependentes desse ambiente.

\section{AGRADECIMENTOS}

Ao IFMA/Campus Codó, a UFMA/Campus Codó e ao Grupo de Pesquisa em Ensino de Química do Maranhão (GPEQUIMA - <www.gpequima.net>).

\section{REFERÊNCIAS}

BONOTTO, D. M. B.; SEMPREBONE, A. da S. Educação ambiental e educação em valores em livros didáticos de ciências naturais environmental education and values education in science textbooks. Ciência \& Educação, SciELO Brasil, v. 16, n. 1, p. 131-148, 2010.

BRASIL. Parâmetros Curriculares Nacionais: meio ambiente. Brasília: Ministério da Educação, 1998.

Parâmetros curriculares nacionais para o Ensino Médio. Brasília: Ministério da Educação, 2002.
Orientações curriculares para o ensino médio. Brasília: Ministério da Educação, 2006.

CANELOI, T. P. Reciclagem, desenvolvimento sustentável e ICMS. In: Anais do XIX Encontro Nacional do Conpedi. Fortaleza: [s.n.], 2010.

CANGEMI, J. M.; SANTOS, A. M. d.; CLARO, N. S. biodegradação: uma alternativa para minimizar os impactos decorrentes dos resíduos plásticos. Química nova na escola, n. 22, p. 17-21, 2005.

CANTANHEDE, S. C. D. S. Textos da revista Ciência Hoje como recurso didático: análise e possibilidades no uso no ensino médio de química. Dissertação (Mestrado) - Programa de Pós-Graduação em Química, Universidade Federal de São Carlos, 2012.

CASTRO, P. A. P. P. de; TUCUNDUVA, C. C.; ARNS, E. M. A importância do planejamento das aulas para organização do trabalho do professor em sua prática docente. Revista Cientıfica de Educaçao, v. 10, n. 10, p. 49-62, 2008.

CEMPRE. CEMPRE Review. São Paulo: CEMPRE Compromisso Empresarial para Reciclagem, 2013.

DICKMANN, I.; CARNEIRO, S. M. M. Paulo freire e educação ambiental: contribuições a partir da obra pedagogia da autonomia. Revista de Educação Pública, v. 21, n. 45, p. 87-102, 2012.

EIGENHEER, E. M.; FERREIRA, J. A.; ADLER, R. Reciclagem: mito e realidade. Rio de Janeiro: In-Fólio, 2005.

FABRIS, C.; NETO, P. J. S.; TOALDO, A. M. M. Evidências empíricas da influência da família, mídia, escola e pares nos antecedentes e no comportamento de separação de materiais para a reciclagem/empirical evidence of the influence of family, media, school and peers in the separation of materials for recycling. Revista de Administração Contemporânea, Associação Nacional de Pós-Graduação e Pesquisa em Administração, v. 14, n. 6, p. 1134, 2010.

FADINI, P. S.; FADINI, A. A. B. Lixo: desafios e compromissos. Cadernos Temáticos de Química Nova na Escola, n. 1, p. 9 - 18, 2001. Edição Especial.

FARIAS, C. R. D. O.; CARVALHO, W. L. P. D. O direito ambiental na sala de aula: Significados de uma prática educativa no ensino médio. Ciência $e$ Educação, v. 13, n. 2, p. 157-74, 2007. 
ABORDAGEM DO CONTEÚDO POLÍMEROS SINTÉTICOS A PARTIR DA TEMÁTICA LIXO E RECICLAGEM NAS AULAS DE QUÍMICA DO ENSINO MÉDIO: UMA PROPOSTA DIDÁTICA

FONSECA, M. D. J. D. C. F. A biodiversidade e o desenvolvimento sustentável nas escolas do ensino médio de belém (pa). Educação e Pesquisa, v. 33, n. 1, p. 63-79, 2007.

FREIRE, P. Conscientização. São Paulo: Moraes, 1980.

FUSARI, J. C. O planejamento do trabalho pedagógico: algumas indagações e tentativas de respostas. São Paulo: Ideias, 1990.

GOI, M. E. J.; SANTOS, F. M. T. Reações de combustão e impacto ambiental por meio de resolução de problemas e atividades experimentais. Química Nova na Escola, v. 31, n. 3, p. 203-209, Agosto 2009.

JACOBI, P. Educação ambiental, cidadania e sustentabilidade. Cadernos de Pesquisa, n. 118, p. 189-205, 2003.

LUCKESI, C. C. Avaliação da aprendizagem escolar: estudos e preposições. $11^{a}$ Edição. São Paulo - SP: Cortez, 2001.

MACHADO, A. H.; MORTIMER, E. F. Química para o Ensino Médio: Fundamentos, pressupostos e o fazer cotidiano. [S.1.]: Unijuí, 2007.

MASSENA, F.; MARINHO, E. C. P. Educação ambiental: considerações a partir da teoria das necessidades. Juris, n. 16, p. 167-78, 2011.

MICHAELI, W.; GREIF, H.; KAUFMANN, H.; VOSSEBURGER, F.-J. Tecnologia dos plásticos. [S.1.]: Editora Edgard Blücher Ltda, 1995.

NETO, D. V.; KAWASAKI, C. S. A temática ambiental em documentos curriculares nacionais do ensino médio. Revista Ensaio, v. 17, n. 2, p. 483-499, 2015.

OLIVEIRA, A. M. D.; RECENA, M. C. P. O ensino de polímeros na perspectiva da educação dialógica com enfoque em cts. Alexandria: Revista de Educação em Ciência e Tecnologia, v. 7, n. 1, p. 103-126, 2014.

PERRENOUD, P.; THURLER, M. G. As competências para ensinar no século XXI: a formação dos professores e o desafio da avaliação. [S.1.]: Artmed Editora, 2002.

PILETTI, C. Didática Geral. 23. ed. São Paulo: Editora Ática, 2001.

PONTES, A. N.; SERRãO, C. R. G.; FREITAS, C. K. A. D.; SANTOS, D. C. P. D.; BATALHA, S. S. A. O ensino de química no nível médio: Um olhar a respeito da motivação. XIV Encontro Nacional de Ensino de Química. Curitiba, PR, 2008.

RESSETTI, R. R. Química. Francisco Alves - PR: NCT, 2000.

SANTOS, A. S. F. E.; FREIRE, F. H. D. O.; COSTA, B. L. N. D.; MANRICH, S. Sacolas plásticas:

Destinações sustentáveis e alternativas de substituição. Polímeros, v. 22, n. 3, p. 228-37, 2012.

SANTOS, E. T. A. D. Educação Ambiental na Escola: conscientização da necessidade de proteção da camada de ozônio. Dissertação (Mestrado) Monografia - Pós-Graduação em Educação Ambiental da Universidade Federal de Santa Maria, Universidade Federal de Santa Maria, 2007.

SANTOS, K. d.; NETO, J. M. M.; SOUSA, P. A. A. Química e educação ambiental:uma experiência no ensino superior. Química Nova na Escola, v. 36, n. 2, p. 119-125, 2014

SANTOS, V. M. N. D.; JACOBI, P. R. Formação de professores e cidadania: projetos escolares no estudo do ambiente. Educação e Pesquisa, n. 37, p. 263-78, 2011.

SANTOS, W. L. P. D.; MORTIMER, E. F. Uma análise de pressupostos teóricos da abordagem c-t-s (ciência - tecnologia- sociedade) no contexto da educação brasileira. Ensaio - Pesquisa em Educação em Ciências, v. 2, n. 2, p. 1-23, 2000.

SANTOS, W. L. P. D.; SCHNETZLER, R. P. Educação em Química: Compromisso Com a Cidadania. [S.1.]: Ijuí, 2003.

SILVA, P. C. S. D.; SILVA, N. L. S. D.; FEIDEN, A.; ZONIN, W. J.; MROZINSKI, C. R.; CLOSS, M. Estudo da viabiliade econômica do destino final do lixo urbano de marechel cândido rodon, pr. Varia Scientia Agrárias, v. 2, n. 2, p. 119-33, 2011.

SOUZA, G. P. V. D. A.; SANTOS, E. A. D.; JÚNIOR, A. A. D. S. Química para o ensino de ciências. EDUFRN, Rio Grand do Norte, 2011.

SWAMINATHAN, M. S. Expansão da capacidade humana de conservar a biodiversidade. Diversidade., Estratégia Global Da. WRI/UICN/PNUMA. Fundação o Boticário de Proteção a Natureza., 1992.

VALENTIN, L.; SANTANA, L. C. Concepções e práticas de educação ambiental de professores de uma escola pública. Ciência e Educação, v. 16, n. 2, p. 387-99, 2010. 
ABORDAGEM DO CONTEÚDO POLÍMEROS SINTÉTICOS A PARTIR DA TEMÁTICA LIXO E RECICLAGEM NAS AULAS DE QUÍMICA DO ENSINO MÉDIO: UMA PROPOSTA DIDÁTICA

VASCONCELLOS, H. S. R. D.; SPAZZIANI, M.

D. L.; GUERRA, A. F. S.; FIGUEIREDO, J. B. D. A.

Espaços educativos impulsionadores da educação

ambiental. Cad. CEDES, v. 29, n. 77, p. 29-47, 2009.

WATANABE-CARAMELLO, G.; STRIEDER, R. B.;

GEHLEN, S. T. Desafios e possibilidades para a

abordagem de temas ambientais em aulas de física.

Revista Brasileira de Pesquisa em Educação em

Ciências, v. 12, n. 1, p. 205-22, 2012. 